\title{
Produção de Goma Xantana por Cepas Nativas de Xanthomonas campestris a Partir de Casca de Cacau ou Soro de Leite
}

\author{
Denis de M. Diniz, Janice I. Druzian, Samara Audibert \\ Departamento de Engenharia Química, UFBA
}

Resumo: Foi estudada a otimização do processo de produção de goma xantana a partir de casca de cacau ou soro de leite como fonte de carbono, e determinou-se o rendimento da goma obtida pela bioconversão de casca de cacau e soro de leite com a Xanthomonas campestris 1182. A goma foi produzida em meios com potássio e nitrogênio a $25{ }^{\circ} \mathrm{C}, 250 \mathrm{rpm}$ por 120 horas. Os rendimentos foram: $2,335 \mathrm{~g} . \mathrm{L}^{-1}$ para a sacarose; 4,995 g.L.-1 para a casca de cacau seca e 12,01 g.L $\mathrm{L}^{-1}$ utilizando soro de leite. Portanto, é viável a produção de goma xantana utilizando fontes de carbono como a casca de cacau e o soro de leite.

Palavras-chave: Biopolimero, fontes alternativas, goma xantana.

\section{Production of Xanthan Gum by Xanthomonas campestris Strains Native From Bark Cocoa or Whey}

Abstract: The optimization of the production process of xanthan gum from cocoa husks or milk whey as carbon source was studied, and the production rate of gum obtained by the bioconversion of cocoa pods and whey was determined, using Xanthomonas campestris 1182. The gum was produced in a medium with potassium and nitrogen at $25{ }^{\circ} \mathrm{C}, 250 \mathrm{rpm}$ for 120 hours. The results were: $2.335 \mathrm{~g} . \mathrm{L}^{-1}$ for sucrose; 4.995 g.L. $\mathrm{L}^{-1}$ for cocoa dry pods and 12.01 g.L $\mathrm{L}^{-1}$ using whey. Therefore, the production of xanthan gum is feasible upon using carbon sources such as cocoa hulls and whey.

Keywords: Biopolymer, alternative sources, xanthan gum.

\section{Introdução}

Os principais biopolímeros encontrados no mercado são as gomas xantana e as dextranas. A primeira representa a maior parte do mercado, sendo aplicada como aditivos em alimentos (estabilizantes de suspensão líquidas e gelatinizantes) por não apresentar nenhum efeito nocivo à saúde humana ${ }^{[1-3]}$.

Os biopolímeros microbianos são produzidos por diversos gêneros de bactérias, fungos e leveduras ${ }^{[4-6]}$.

A goma xantana é um exopolissacarídeo natural e de grande importância para a indústria de polímeros, sendo descoberta em 1950 pelo Northern Regional Research Laboratories (NRRL) do United States Department of Agriculture. O Polímero B-1459, ou goma xantana, produzido pelas bactérias Xanthomonas campestris NRRL B-1459 foi muito estudado por causa das suas propriedades ${ }^{[6]}$. É utilizada na indústria petrolífera, no entanto, só é viável como grau alimentício devido ao alto custo da fonte de carbono utilizada no meio fermentativo, tal como glicose ou sacarose, que representa $50 \%$ do custo final da goma.

Entre as técnicas mais promissoras, na recuperação avançada de petróleo, destaca-se a aplicação de polímeros. Estudos demonstram que a correta aplicação dos polímeros pode aumentar as atuais reservas em cerca de $50 \%$. Paralelamente, com a injeção de polímeros, ocorre a redução da produção de água nos poços de petróleo, tendo como consequiência a redução de custos de descarte de água com efeitos ambientais positivos ${ }^{[7,8]}$.

O biopolímero que a Xanthomonas produz pode ser obtido por fermentação em diferentes meios de cultura, com os mais variados rendimentos, massas molares e composição da goma, o que interfere diretamente na sua composição química e conseqüentemente nas propriedades reológicas.
As agroindústrias de processamento de cacau e de queijos produzem quantidades consideráveis de resíduos, que normalmente são descartados no meio ambiente, mas que podem ser utilizados como fonte de carbono no meio fermentativo.

A utilização de soro de leite para produção de goma xantana depende da bactéria de Xanthomonas apresentar enzima com atividade galactosidase para hidrolisar a lactose $\mathrm{e}^{[3]}$.

Diversos pesquisadores usaram outros substratos alternativos para produzir goma xantana, tais como extrato de alfarroba ${ }^{[9]}$, água de lavagem de moinho de azeitona ${ }^{[10]}$, resíduos de citros $^{[11,12]}$, ácido cítrico $^{[13]}$ e soro de leite ${ }^{[14,15]}$. Todos obtendo resultados favoráveis a utilização de fontes de carbono alternativas.

Selecionar fontes de carbono para Xanthomonas, para obter polissacarídeos em quantidade e com propriedades economicamente interessantes é um desafio que vem sendo enfrentado por vários grupos de pesquisa. Portanto, embora a tecnologia para produzir goma xantana está sedimentada a partir de sacarose como substrato, é necessário em paralelo estudar fontes de carbono alternativas que possam ser viáveis. Neste sentido, o objetivo deste trabalho é viabilizar a produção de goma xantana utilizando a casca de cacau e o soro de leite como fonte viável.

\section{Materias}

O álcool etílico utilizado na precipitação da goma foi grau comercial. A peptona bacteriológica e o extrato de malte foram obtidos, respectivamente, da Inlab e da Acumedia. Os demais componentes químicos (Agar Agar puro, D(+) Glucose Anidra P.A., D(+) Sacarose P.A., Extrato de levedura, D(+) Lactose P.A., $\mathrm{K}_{2} \mathrm{HPO}_{4}$ P.A., $\mathrm{NH}_{4} \mathrm{Cl}, \mathrm{MgSO}_{4},\left(\mathrm{NH}_{4}\right)_{2} \mathrm{HPO}_{4}$, Uréia e $\left.\mathrm{KH}_{2} \mathrm{PO}_{4}\right)$ foram comprados da Vetec.

Autor para correspondência: Denis de M. Diniz, Departamento de Engenharia Química, Universidade Federal da Bahia - UFBA, Aristides Novis, no 2, Federação, CEP 40210-630, Salvador, BA, Brasil, e-mail: denismdiniz@yahoo.com.br 
Incubadora Tecnal TE 398/2; Estufa com circulação de ar Nova Ética, autoclave vertical Alpha, Mufla Lavoisier, Balança analítica Sartorius BL 210S, Shaeker Tecnal TE 424, e determinador de nitrogênio Tecnal TE 036/1, Banho de água Dubnoff Nova Ética, Espectrofotômetro Lambda 20 Perkin Elmer, além de acessórios em geral.

Cepas: Foram utilizadas: 1198 - Xanthomonas campestris pv. arracaciae; 1779 - Xanthomonas campestris pv. malvacearum; 1182 - Xanthomonas campestris manihotis; 472 - Xanthomonas campestris pv. campestris. Todas as cepas foram doadas pelo Instituto Biológico de Campinas - SP.

Casca de cacau: A quantidade de $25 \mathrm{~kg}$ de resíduo foi coletada no beneficiamento de cacau de uma fazenda no sul da Bahia.

Soro de leite: A quantidade de $9 \mathrm{~L}$ foi coletada da produção de queijo realizada no laboratório de pescado (LAPESCA). Composição centesimal dos resíduos utilizados na fermentação por Xanthomonas. Os teores de umidade, proteína, cinzas e fibra foram determinados segundo metodologia da $\mathrm{AOAC}^{[16]}$. O conteúdo de lipídios foi determinado pelo método de BLIGH \& DYER ${ }^{[17]}$.

\section{Metodologia}

\section{Cepas}

As cepas de Xanthomonas usadas para produção de goma xantana foram mantidas em meio yeast manitol (YM) sólido Agar com repicagens periódicas semanais para a manutenção.

\section{Preparação dos resíduos}

A Casca de cacau in natura foi fatiada e seca em estufa a $110^{\circ} \mathrm{C}$ por 12 horas, depois foi triturada em multiprocessador, em seguida as partículas de maior diâmetro foram retiradas com auxilio de peneira de tyler $42 \mathrm{com}$ abertura de $355 \mathrm{~mm} . \mu \mathrm{m}^{-1}$. O pó resultante foi acondicionado em 50 recipientes de $500 \mathrm{~g} \mathrm{a}-18{ }^{\circ} \mathrm{C}$.

$\mathrm{O}$ soro de leite foi autoclavado $\left(121{ }^{\circ} \mathrm{C} / 15\right.$ minutos $)$ e acondicionado em nove recipientes de $1 \mathrm{~L}$ à $-18^{\circ} \mathrm{C}$.

$\mathrm{O}$ pó de casca de cacau e o soro de leite eram descongelados somente no momento do preparo dos meios para a fermentação.

\section{Produção de goma xantana}

As etapas de obtenção de goma xantana produzida seguem a seqüência do fluxograma abaixo, conforme Figura 1.

\section{Repicagem das cepas}

Foi utilizado o meio composto de: Extrato de malte, Extrato de Levedura, Peptona Bacteriológica, Glicose e Agar. Os reagentes foram dissolvidos em $100 \mathrm{~mL}$ de água destilada, (pH ajustado para 7,0), Agar, foi adicionado seguido de aquecimento até completa dissolução e desaparecimento da opacidade. O meio foi distribuído em tubos de ensaio, fechados com algodão, depois autoclavados por $121{ }^{\circ} \mathrm{C} / 15$ minutos. Os tubos foram inclinados em bancada até o equilíbrio com a temperatura ambiente local e solidificação do meio. A repicagem com Xanthomonas campestres foi realizada com alça de platina por raspagem, e mantido em estufa por 48 horas para crescimento da colônia.

\section{Obtenção do tempo de inoculação}

Para monitorar o crescimento das bactérias de Xanthomonas campestris, a produção de goma no meio e obtenção do ponto ótimo de inoculação, foram realizadas medidas de absorbância em espectrofotômetro UV $\lambda(620 \mathrm{~nm})$ ao longo do período de inoculação. Neste experimento foram preparados oito erlenmeyers contendo o meio YM, segundo a metodologia adotada. $\mathrm{O}$ meio foi autoclavado, inoculado com as cepas e mantido em incubadora a $250 \mathrm{rpm}, 28{ }^{\circ} \mathrm{C}$ por 100 horas. O fermentado $\mathrm{n}^{\circ} 1$ (tempo zero de fermentação) foi utilizado como branco e os seguintes foram lidos em intervalos de 12 horas consecutivas.

\section{Inóculo}

O meio YM (Meio I) foi dissolvido em $400 \mathrm{~mL}$ de água destilada, (pH ajustado 7,0). Transferiu-se $50 \mathrm{~mL}$ do meio YM para 08 erlenmeyers de $250 \mathrm{~mL}$ e autoclavados $\left(121{ }^{\circ} \mathrm{C} / 15\right.$ minutos $)$. Depois deixados em repouso até equilíbrio com a temperatura ambiente local. Após o equilíbrio foi realizada a inoculação com células viáveis obtidas na repicagem. Em seguida foram fermentados em Shaker a $28^{\circ} \mathrm{C} .250 \mathrm{rpm}^{-1} / 48$ horas. O mesmo foi feito para os meios II e III. As composições dos meios encontram-se na Tabela 1.

\section{Fermentação}

No primeiro método de fermentação 08 erlenmeyers de $250 \mathrm{~mL}$, contendo $80 \mathrm{~mL}$ de meio fermentativo composto por uréia, fosfato monobásico de potássio e sacarose como fonte de carbono, (pH ajustado para 7,0), receberam cada um $16 \mathrm{~mL}$ do inóculo. A fermentação foi realizada em Shaker a $28^{\circ} \mathrm{C} .250 \mathrm{rpm}^{-1} / 120$ horas.

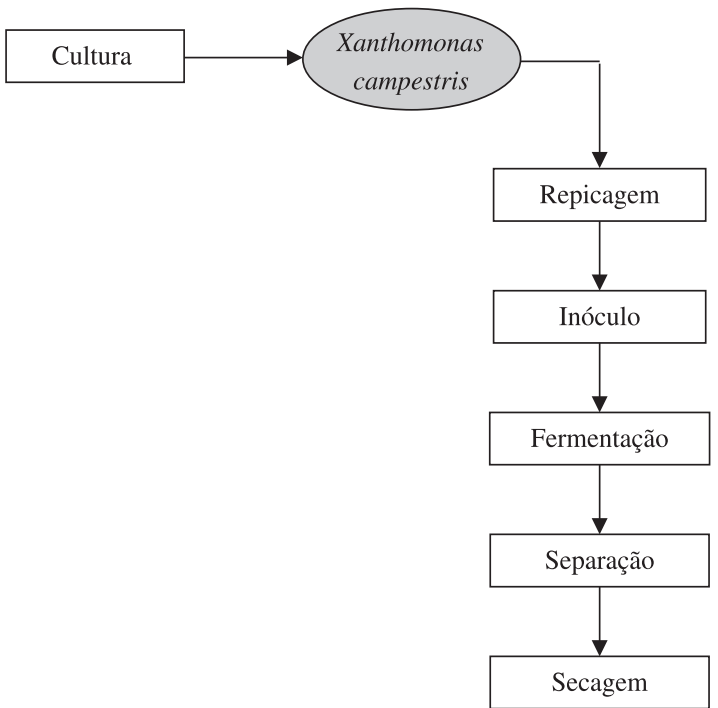

Figura 1. Fluxograma utilizado para obtenção de goma xantana a partir de sacarose, casca de cacau seca e soro de leite integral.

Tabela 1. Composição dos meios utilizados no inóculo.

\begin{tabular}{lccc}
\hline & \multicolumn{3}{c}{ Meios } \\
\cline { 2 - 4 } & I & II & III \\
\hline Extrato de levedura & $0,3 \%$ & $0,1 \%$ & $0,15 \%$ \\
Malte & $0,3 \%$ & - & $0,15 \%$ \\
Peptona & $0,5 \%$ & - & $0,25 \%$ \\
Sacarose & $1 \%$ & - & - \\
Glicose & - & - & $1,2 \%$ \\
Lactose & - & $1,5 \%$ & - \\
$\mathrm{K}_{2} \mathrm{HPO}$ & - & $0,5 \%$ & $0,25 \%$ \\
$\mathrm{NaCl}_{4}$ & - & $0,1 \%$ & - \\
$\mathrm{MgSO}_{4}$ & - & $0,01 \%$ & - \\
$\mathrm{NH}_{4} \mathrm{Cl}$ & - & $0,2 \%$ & - \\
$\left(\mathrm{NH}_{4}\right)_{2} \mathrm{HPO}_{4}$ & - & - & $0,15 \%$ \\
\hline
\end{tabular}


No segundo método de fermentação o mesmo foi feito, mas nesta fermentação mudou-se a fonte de carbono, sendo utilizada a casca de cacau no lugar da sacarose, que foi deixada sob agitação no solvente (água) por 30 minutos com posterior filtragem para melhor obtenção da fonte de carbono.

O terceiro método de fermentação utilizou o soro de leite como solvente da uréia e do fosfato monobásico de potássio a sacarose foi retirada, pois o soro de leite também é a fonte de carbono.

Foi obtida a concentração ótima de fonte de carbono no meio fermentativo através de um estudo variando a concentração da fonte de carbono entre 1 a $11 \%$.

\section{Isolamento da goma xantana}

As gomas obtidas dos três métodos de fermentações foram isoladas do meio de cultura por precipitação com etanol $96 \%$ na proporção, meio:álcool de 1:3 (v/v).

\section{Secagem da goma xantana}

Depois de separado o precipitado foi seco a $30 \pm 2{ }^{\circ} \mathrm{C}$ e triturado para avaliação dos rendimentos ( $\mathrm{g}$ de goma/ $\mathrm{L}$ de meio de fermentação) e estudo da viscosidade aparente das gomas. A massa de goma produzida foi avaliada gravimetricamente.

\section{Resultados}

As bactérias, 1198 - Xanthomonas campestris pv. arracaciae; 1779 - Xanthomonas campestris pv. malvacearum; 1182 Xanthomonas campestris manihotis; 472 - Xanthomonas campestris pv. Campestris foram inoculadas e fermentadas. Os rendimentos obtidos para a bioconversão em goma xantana pelas diferentes cepas de Xanthomonas são apresentados na Tabela 2:

De acordo com a Tabela 2, pode-se observar que todas as cepas formaram goma xantana na primeira produção, mas apenas quatro precipitaram em presença de álcool: duas com meio fermentativo padrão que utilizou sacarose (cepas 1182 e 1198) e duas com o meio fermentativo que utilizou o resíduo (cepas 1182 e 1198).

Na segunda produção observa-se que, apenas as cepas 1182 e 1779 formaram goma precipitável em álcool. As demais cepas não formaram goma. Na terceira produção houve precipitação apenas da goma formadas pelas cepas 1182 e 472 .

Segundo Shu et al. (1990) $)^{[18]}$ e Xueming et al. (1991) ${ }^{[19]}$ o isolamento e a seleção de colônias de Xanthomonas campestris do habitat natural, assim como, a otimização das condições de fermentação são ferramentas importantes para melhorar a produção de goma xantana. A colônia microbiana, junto com outras condições de processo, isto é composição do meio de cultura, modo de agitação (oxigênio dissolvido), e o tempo de fermentação determinam a produtividade e a qualidade da goma.

A cepa 1182 foi selecionada por ter sido a que se apresentou mais produtiva dentre as quatro cepas testadas, a produção de goma xantana com esta cepa e casca de cacau seco alcançou maior repetibilidade nos valores do rendimento.

O período de crescimento microbiano máximo observado por Rottava (2005) ${ }^{[20]}$ através de medidas de absorbância no comprimento de onda igual a $560 \mathrm{~nm}$ foi de 16 a 40 horas para vários tipos de Xanthomonas. A Figura 2, espectrofotômetro no comprimento de onda igual a $640 \mathrm{~nm}$, mostra a curva de crescimento celular da cepa 1182 acompanhada da produção de biomassa no meio inóculo, onde é observado um patamar máximo de absorvância no intervalo entre 40-70 horas, com a subsequiente queda, devido ao consumo da fonte de carbono (sacarose) pelas bactérias. Pode-se observar que o ponto ótimo da fase log ocorre entre 40-70 horas de inoculação a temperatura de $28^{\circ} \mathrm{C}$ com agitação de $250 \mathrm{rpm}$, sendo adotado o período de inoculação de 48 horas.

O estudo feito, com sacarose, para obtenção da melhor concentração de fonte de carbono no meio fermentativo mostrou que a concentração ótima está em $1 \%$ o meio com $3 \%$ também formou, mas com rendimento menor. Os meios com 5, 7, 9 e $11 \%$ não formaram goma devido à alta pressão osmótica do meio que comprometeu a divisão celular.

Com a lactose foi obtido um rendimento de 3,72 g.L. $\mathrm{L}^{-1}$, o estudo inicial com a lactose mostrou que a cepa 1182 é capaz de utilizar essa fonte de carbono para a produção de goma xantana.

Dois métodos de fermentação com o soro de leite foram realizados para a produção de goma. No primeiro teste o meio fermentativo foi produzido sem uréia. Constatou-se, que não houve formação de goma provavelmente devido à falta de uréia (ponte de nitrogênio), nutriente indispensável para a bactéria, apesar do soro apresentar de 2,61 a 2,66\% de proteína bruta. Este nitrogênio orgânico provavelmente não foi disponibilizado às bactérias para a multiplicação celular, enquanto a forma inorgânica normalmente permite esta disponibilidade.

No segundo teste, com a adição de uréia no meio fermentativo obteve-se um grande rendimento, superando inclusive os valores obtidos com $2 \%$ sacarose e casca de cacau, nas mesmas condições fermentativas.

A Tabela 3 mostra os resultados obtidos a partir da otimização da produção de goma xantana com os resíduos (casca de cacau e soro de leite) e sacarose.

Tabela 2. Goma xantana obtida com diferentes cepas de Xanthomonas, com sacarose e casca de cacau seca, $28{ }^{\circ} \mathrm{C}, 250 \mathrm{rpm}, 120$ horas de fermentação.

\begin{tabular}{|c|c|c|c|c|c|c|}
\hline \multirow[t]{2}{*}{ Cepas } & \multirow{2}{*}{$\begin{array}{c}\text { Meio } \\
\text { Fermentativo }\end{array}$} & \multicolumn{3}{|c|}{ Produção / Rendimento } & \multirow[t]{2}{*}{ Média } & \multirow{2}{*}{$\begin{array}{l}\text { Desvio } \\
\text { padrão }\end{array}$} \\
\hline & & $\begin{array}{c}1^{\mathbf{0}} \\
\left(\mathrm{g} . \mathrm{L}^{-1}\right)\end{array}$ & $\begin{array}{c}\mathbf{2}^{\mathbf{o}} \\
\left(\mathrm{g} . \mathrm{L}^{-1}\right)\end{array}$ & $\begin{array}{c}3^{\mathbf{o}} \\
\left(\text { g. } \mathrm{L}^{-1}\right) \\
\end{array}$ & & \\
\hline \multirow[t]{2}{*}{1182} & Sacarose & 2,16 & 2,12 & 2,48 & 2,25 & $\pm 0,1600$ \\
\hline & $\begin{array}{l}\text { Resíduo de } \\
\text { cacau }\end{array}$ & 2,20 & 5,27 & 8,81 & 5,42 & $\pm 2,7011$ \\
\hline \multirow[t]{2}{*}{472} & Sacarose & + & 1,78 & + & 1,78 & - \\
\hline & $\begin{array}{l}\text { Resíduo de } \\
\text { cacau }\end{array}$ & + & 0,65 & + & 0,65 & - \\
\hline \multirow[t]{2}{*}{1198} & Sacarose & 0,64 & - & + & 0,64 & - \\
\hline & $\begin{array}{l}\text { Resíduo de } \\
\text { cacau }\end{array}$ & 1,15 & - & + & 1,15 & - \\
\hline \multirow[t]{2}{*}{1779} & Sacarose & + & - & 1,40 & 1,40 & - \\
\hline & $\begin{array}{l}\text { Resíduo de } \\
\text { cacau }\end{array}$ & + & - & 3,45 & 3,45 & - \\
\hline
\end{tabular}

$(+)=$ Houve formação de goma, mas não precipitou.

$(-)$ = Não houve formação.

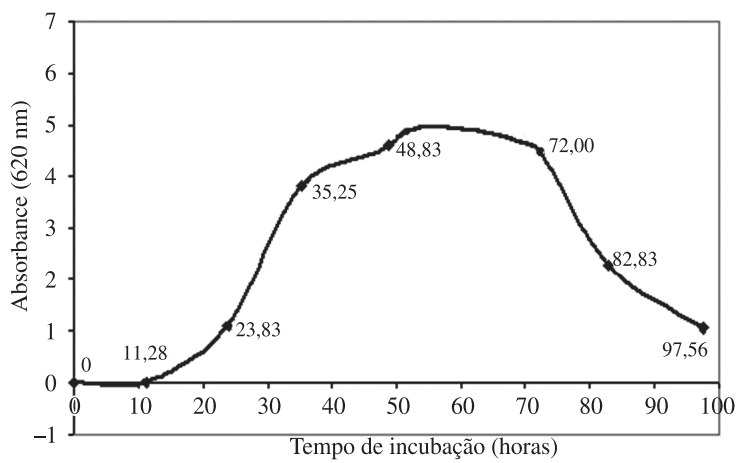

Figura 2. Curva de crescimento da biomassa do inóculo pela cepa 1182, $28^{\circ} \mathrm{C}, 250 \mathrm{rpm}$ a $620 \mathrm{~nm}$. 
Tabela 3. Produção de goma xantana obtida após a otimização dos processos e meios fermentativos. $28^{\circ} \mathrm{C}, 250 \mathrm{rpm}, 120$ horas.

\begin{tabular}{llrl}
\hline \multicolumn{1}{c}{ Cepas } & $\begin{array}{c}\text { Meio } \\
\text { fermentativo }\end{array}$ & $\begin{array}{c}\text { Produção } \\
\text { média } \\
\text { g.L. }\end{array}$ & $\begin{array}{c}\text { Desvio } \\
\text { padrão }\end{array}$ \\
\hline 1182 - Xanthomonas campestris & Sacarose & 2,42 & $\pm 0,62$ \\
pv. manihotis & Casca de cacau & 7,34 & $\pm 0,41$ \\
& Soro de leite & 12,01 & $\pm 0,65$ \\
\hline
\end{tabular}

Druzian \& Pagliarini (2007) ${ }^{[21]}$ estudaram a produção de goma xantana por fermentação do resíduo de suco de maçã fuji com cepas de Xanthomonas campestris pv. manihotis em condições semelhantes as utilizadas no presente estudo. A fermentação a $28{ }^{\circ} \mathrm{C} .150 \mathrm{rpm}^{-1}$ produziu na condição otimizada, $45 \mathrm{~g} . \mathrm{L}^{-1}$ de meio, que representou um rendimento 10 vezes maior do que o obtido com sacarose. Rottava (2005) ${ }^{[20]}$ Estudando a mesma cepa com condições de agitação diferente e um meio fermentativo mais complexo obteve um rendimento de 7,97 g. $\mathrm{L}^{-1}$ de goma xantana.

Nitschke \& Rodrigues (2000) $)^{[22]}$ no seu estudo de virulência da Xanthomonas campestris, retiradas de diferentes vegetais, obtiveram uma produção de goma xantana entre 8,3 a 13,5 g.L ${ }^{-1}$. Antunes et al. (2000) ${ }^{[23]}$ trabalhando com triagem em cepas de Xanthomonas campestris pv. pruni obtiveram concentrações variáveis, sendo a mais eficiente de 26,4 g.L $\mathrm{L}^{-1}$. Bastos et al. (2005) ${ }^{[24]}$ e Mayer et al. (2005) ${ }^{[25]}$ estudando a cepa Xanthomonas campestris pv. vesicatória obtiveram nos dois trabalhos um rendimento de 5,85 g. $\mathrm{L}^{-1}$ com alterações apenas na quantidade de piruvato e acetil.

Existem alguns estudos que testaram a utilização do soro de leite para a produção de goma xantana. ${ }^{[3]}$ Produziram goma a partir de soro de leite com Xanthomonas campestris $\mathrm{C}_{7} \mathrm{~L}$ atingindo uma produção media de 12,21 g.L. $\mathrm{L}^{-1}$ com o soro hidrolisado, 14,7 g.L. ${ }^{-1}$ com o soro integral e 11,8 g... $\mathrm{L}^{-1}$ com o soro filtrado. Fornari (2006) ${ }^{[26]}$ utilizou o soro de queijo mussarela para a produção de goma xantana e obteve um rendimento de 13,70 g.L. $\mathrm{L}^{-1}$ e com soro de queijo prato obteve 7,81 g.L $\mathrm{L}^{-1}$. Valores próximos aos obtidos neste trabalho.

\section{Conclusão}

Das quatro linhagens estudadas, a melhor para produção de goma xantana foi a Xanthomona campestre manihotis - 1182, em termos de produção obtida com resíduos de agroindústria Baiana.

Constatou-se que é possível e viável produzir Goma Xantana utilizando a cepa 1182 e resíduos da agroindústria Baiana no meio fermentativo, do tipo casca de cacau seca e soro de leite.

Um melhor rendimento de produção de goma foi obtido com a cepa 1182 utilizando o meio fermentativo com soro de leite, obtendo-se uma produtividade 1,2 vezes maior do que com o meio com glicose, 1,6 vezes maior do que com resíduo de casca de cacau e 1,5 vezes maior do que com sacarose.

Vale salientar que as cepas de Xanthomonas campestris utilizadas nesse estudo são cepas nativas, isoladas de vegetais da região sudeste.

\section{Referências Bibliográficas}

1. Villen, R. A. - Biotec. Hist. Tend. (2002).

2. Moreira, A. S.; Souza, A. S. \& Vendrusculo, C. T. - Rev. Bras. Agroc., 4 (1998).
3. Nitschke, M.; Rodrigues, V. \& Schinatto, L. F. - Cienc. Tecnol. Aliment., 21, p.82 (2001). http://dx.doi.org/10.1590/S010120612001000100018

4. Padilha, F. F. - "Produção de Biopolímeros sintetizados por microorganismos", Tese de Doutorado, Universidade Estadual de Campinas, Brasil (2003).

5. Crescenzi, V. - Biotechnol. Prog., 11, p.251 (1995). PMid:7619395. http://dx.doi.org/10.1021/bp00033a002

6. Garcia-Ochoa, F.; Santos, V. E.; Casas, J. A. \& Gomez, E. - Biotechnol. Adv., 18, p.1 (2000).

7. Correia, D. Z.; França, F. P. \& Mothe, C. G. - Conjunt. Inform, 31, p.1 (2006).

8. Kimura, R. M. - "Indústria brasileira de petróleo: uma análise da cadeia de valor agregado", Monografia do Graduação, Universidade Federal do Rio de Janeiro, Brasil (2005).

9. Roseiro, J. C.; Costa, D. C. \& Collaco, M. T. A. - Food sci. Technol., 25, p.289 (1992).

10. Lopez, M. J. \& Ramos-cormenaza, A. - Int. Biodeterior. Biodegrad., 38, p.263 (1996).

11. Green, M.; Shelef, G. \& Bilanovic, D. - Chem. Eng. J., 56, p.37 (1994).

12. Bilanovic, D.; Shelef, G. \& Green, M. - Bioresour. Technol., 48, p.169 (1994). http://dx.doi.org/10.1016/0960-8524(94)90205-4

13. Jana, A. K. \& Ghosh, P. - J. Ferm. Bioeng., 80, p.485 (1995). http:// dx.doi.org/10.1016/0922-338X(96)80924-X

14. Yang, S. T. \& Silva, E. M. - J. Dairy Sci., 78, p.2541 (1995). http:// dx.doi.org/10.3168/jds.S0022-0302(95)76884-9

15. Konicek, J.; Lasik, J. \& Safar, H. - Fol. Microbiol., 38, p.403 (1993).

16. Association of Official Analytical Chemists - AOAC. - "Official Methods of Analysis oh the AOAC", AOAC, v.16, p.1141 (1995).

17. Bligh, E. G. \& Dyer, W. J. - Can. J. Biochem. Physiol., 37, p.911 (1959). http://dx.doi.org/10.1139/o59-099

18. Shu, C. H. \& Yang, S. T. - Biotechnol. Bioeng., 35, p.454 (1990). PMid:18592538. http://dx.doi.org/10.1002/bit.260350503

19. Xueming, Z.; Nienow, A.W.; Kent, C. A.; Chatwin, S. \& Galindo, E. - "Improving xanthan fermentation performance by changing agitators" in: Proceedings of the $7^{\circ}$ European Conference on Mixing, p.277, Brugge, Sep (1991).

20. Rottava, I. - "Seleção de linhagens de Xanthomonas sp para a produção de goma Xantana”, Dissertação de mestrado, UniversidadeRegional Integrada do Alto Uruguai e das Missões, Brasil (2005).

21. Druzian, J. I. \& Pagliarini, A. P. - Cienc. Tecnol. Aliment., 27, p.26 (2007). http://dx.doi.org/10.1590/S0101-20612007000100005

22. Nitschke, M. \& Rodrigues, V. - Bras. J. Microbiol., 31, p.58 (2000). http://dx.doi.org/10.1590/S1517-83822000000100014

23. Antunes, A. E.; Moreira, A. S.; Vendruscolo, J. L. S. \& Vendrusculo, T. C. - Ciên. Eng., 9, p.83 (2000).

24. Bastos, C. P.; Mayer, L.; Monks, L.; Michels, R. A.; Vendrusculo, C. T. \& Moura, A. B. - "Correlação entre produção, viscosidade e teor de acetil no biopolímero de 5 cepas de Xanthomonas", in: Anais do $14^{\circ}$ Congresso de iniciação científica, Pelotas, (2005).

25. Mayer, L.; Bastos, C. P.; Monks, L.; Michels, R. A.; Vendrusculo, C. T. \& Moura, A. B. - "Correlação entre produção, viscosidade e teor de piruvato no biopolímero de 5 cepas de Xanthomonas." in: Anais do $14^{\circ}$ Congresso de iniciação científica, Pelotas, (2005).

26. Fornari, R. C. G. - "Aproveitamento de soro de queijo para a produção de goma xantana”, Dissertação de Mestrado, Universidade Regional Integrada do Alto Uruguai e das Missões, Brasil (2006).

Enviado: 03/11/10

Reenviado: $22 / 08 / 11$

Aceito: 04/09/11 